\title{
Correlation Between Learning Styles and Readiness for Self-Directed Learning Among Nursing Students
}

\author{
Samina Khadim \\ Lahore School of Nursing, Name of organization, The University of Lahore, Lahore, Pakistan
}

\begin{abstract}
Background: Learning is a continuous process which occur throughout the individuals' lives. When one teaches to others, it is a contribution to developing ones' attitudes, values and behaviors at the professional level while there remains a partnership of accountability between teacher and learner (Gebru, Sh, \& Mohammadi, 2015). Professional development in nursing demands the acquisition of skills that promote continuing and lifelong learning outside the formal education Programme for the purpose of keeping well informed with new knowledge and skills applying to professional nursing practice. Self-directed learning is one such vital skill identified as crucial for students and nursing practitioners (Rensburg \& Botma, 2015.Objective: To see the association between learning styles and readiness for self-directed among nursing students.Method: A correlational research design was used for this study. The study was carried out among 0ne hundred and forty nursing students in University of Lahore. Convenient sampling technique was used, and adopted questionnaire was distributed among participants.Results: There was the significant positive correlation between learning styles and readiness for selfdirected. Which was checked by Pearson correlation test on SPSS version 23. The significant correlation value was 1 and.233.The significant value was $>0.05$. Conclusion: Findings of the study concluded that learning Styles and readiness for self-directed had significant positive correlation with each other.
\end{abstract}

Keywords. Learning Styles, Self-directed learning, Readiness,Self-Efficacy, part Time Education.

DOI: $10.7176 / \mathrm{JHMN} / 62-15$

Publication date:May $31^{\text {st }} 2019$

\section{INRODUCTION}

One of the key features of self-directed learning remains it aims to train people regardless of the situation. This is because of the fact that self-directed learning allows learners to use their own initiatives for learning process that includes need identification, formulation and development of learning objectives, identification of resources, selection as well as implementation of learning strategies and assessment of learning outcomes (Ranvar, 2015) Self-directed learning (SDL) has been identified as an approach to learning that received increasing attention in recent years, particularly in the context of higher education. Self-directed learning has been shown to be associated with increased curiosity, critical thinking, quality of understanding, retention and recall, better decision making, achievement satisfaction, motivation, competence and confidence. It is a popular approach for learning in nursing education as it provides a valuable approach with regards to demands of the nursing profession (Shen, Chen, \& $\mathrm{Hu}, 2014)$.

According to Malcolm Knowles, self-directed learning is the mechanism by which a person — with or without the help of others - identifies his/her learning needs, sets goals to address these learning needs, determines the human and non-human resources, implements strategies to address these learning needs and evaluates his knowledge . Knowles forecast that self-directed learning would be vital for humans to survive in the world of innovation (Prabjandee \& Inthachot, 2013). SDL is associated with benefits related to an improved quality of nursing practice and professional development and an opportunity for knowledge expansion for nursing students with critical thinking, sound decision-making, achievement satisfaction, enthusiasm, competence and self-reliance enhanced (Shen et al., 2014).

Encouraging nursing students to become self-directed and lifelong learners is highlighted as an important goal of nursing education (Qamata-Mtshali, 2014).

Students' ability to engage effectively in SDL is referred to as Readiness for SDL (Fisher \& King, 2015).

Students' readiness for self-directed learning is influenced by the role of the facilitator of learning, the facilitation process, the facilitator-student relationship, a student's readiness to learn, willingness to take responsibility and the degree of motivation within students. The teaching methods being utilized need to encourage active participation to promote the skills of self-directed learning.

Hence, in order to apply SDL in right direction, it is important to assess learner's readiness. Self-directed learning readiness can be defined as the features of personality, attitude and talent required for self-directed learning. There is higher initiative of learning and better learning when there is higher readiness to self-directed learning. It is prime for the individuals with lower self-directed learning readiness to strengthen it (Örs, 2018).

In order to determine level of self-directed learning readiness among nursing students, self-directed learning readiness scale (SDLRS) used. The 40-item SDLRS was first developed by Fischer et al. 2001 and is designed to assess students' readiness for self- directed learning that consists of three subscales: self-management (13 items) 
reflects the characteristics of being able to manage one's own learning, desire for learning (12 items) relating to the desire for learning., and self-control (15 items) related to the features self-control and being in control of one's own learning. Self-control is an attribute of SDL that enables the learner to take responsibility for his or her own learning. Thus, the learners take control, taking decisions on what to learn or not to learn based on their learning needs. To engage in the critical processes that are necessary for self-control, the learners have to be fully conscious of their activities. Self-control practice provides learners with the critical thinking skills necessary to achieve autonomy. Those students who are self-directed may have high personal expectations, high personal abilities and they have set their study time very well (Adeoye-Agboola \& Evans, 2015).

Learning style is defined as the biological and developmental characteristics that are used by the individuals for concentrating, processing, internalizing and retaining information that is either new or difficult (Gebru et al., 2015).

There has been rapid change in science that also brings need for an information explosion. Hence, the nurses have to be trained for possessing readiness for SDL and that in their academic stage. In this way, when the nurses are ready for self-directed learning, they are open to change and are also able to sustain their professional development. Besides this, SDL allows nurses to develop implementation skills as well as self-confidence. Hence, it can be deducted that SDL acts as an important element for sustainability in terms of nursing education (AbuAssi \& Alkorashy, 2016).

A four stage learning cycle is developed by educational theorist and psychological David Kolb that describes how the process of learning by experience takes place. This cycle of experiential learning is made up of four phases that are: abstract conceptualization (AC) concrete experience (CE)active experimentation (AE)reflective observation (RO)v(Gebru et al., 2015).

The Kolb's experiential Learning Cycle theory represents a learning cycle with four stages in which below mentioned four bases are touched by the learner (1) Concrete Experience in which there is fresh experience about a particular situation or there is re-interpretation of any existing experience.(2)Reflective Observation that means experience occurs and many inconsistencies are found between the actual situations versus predicted ones.(3)Abstract Conceptualization that means new idea emerges from reflective thinking or some modifications are made in concept existing at abstract level (4)Active Experimentation that means application of concepts by the learner on real-world scenario that lead to learn about real outcomes (McLeod, 2010).

Learning styles (inclusive of self-directed learning) act as important features of education in nursing field. There is a strong need in nursing education of assessment of learning styles so that the nursing educators are able to choose most suitable teaching strategies as these allow the nursing teachers to envisage the differences in the interests, abilities and needs of different learners. Such understanding is critical for the educators as it allows managing adult learners efficiently and effectively (AbuAssi \& Alkorashy, 2016).

Studies show that there is significant relationship of the students' learning capabilities with number of factors such as personal flexibility, gender, academic accomplishments, learning preferences, background of clinical education and retention. Hence, there is significant influence of self-directed learning readiness with the students' preferred learning style. When student chooses SDL, he or she has to ensure that he or she masters the goals and objectives of that education program in response to the selection SDL.

\section{Statement of the problem}

Teaching methods used by the academic staff in universities are selected based on the experience of teacher or the nature of the course. However, the selection does not consider the learning readiness as well as the learning styles of the students who are to be taught. Given the importance of learning styles and SDL especially in nursing education field, it is worthy to study the relationships between given variables (AbuAssi \& Alkorashy, 2016).

A number of studies have explored relationship of self-directedness with the learning styles but any conclusive evidence is absent that confirms if self-directedness relates to a specific learning style. Hence, it remains a query if there is connection of SDL with any particular learning style.

Using theory of learning by Kolb for this purpose is helpful as it promotes of adult learning by defining the skills for active as well as interactive learning. Hence, besides SDL, Kolb's theory is significant for adult leaning also. The theory emphasizes need of learners to be self-directed (El-Gilany \& Abusaad, 2013). In the light of above mentioned details, this study determines if there is any significant relationship between SDL and learning styles.

\section{Significance of the study}

The significance of the study is that this study will contribute and serve as ground for further researches in the relevant field. Moreover, studying learning styles' relationship with self-directed learning will serve as an important tool in enhancing self-directed learning and the tool can be used by academia as well as clinical setting to better boost the processes of products of self-directed learning. The findings of this study could help nurse educators to assist students acquire strategies to develop the skills and characteristics of self-control, selfmanagement and desire for learning application in educational and clinical practice settings. Understanding the learning styles of nursing students can drive the institutions to adapt instructional materials to enhance students' 
learning of knowledge and skills. It seems to be clear that students possess right skills to analyze and utilize the information in effective manner. It is also noted that self-directed learning requires changing the approach of teaching as focus shifts to facilitation to learner. SDL is been used increasingly as the method of teaching and learning in nursing education and thus there is clear need of assessing SDLR and appropriate learning style preference by students, so that appropriate teaching and learning methods can be used by the educators.

\section{LITERATURE REVIEW}

Students of any discipline are well aware to choose any type of learning style and learning strategies to enhance their readiness for self- directed, as well as their better academic performance. Therefore, it is recommended that, if the nurse educators will assess and assist their students in identifying their own style preferences and learning, then academic performance of students will be increased. A number of studies have been carried out in order to determine the relationship of learning styles with self-directed learning. A similar study was conducted among nursing students, to determine the correlation between learning styles and readiness for self-directed learning. Findings of this study revealed a significant relationship between total mean SDLR score and learning styles among nursing students. Comparison of socio-demographic groups revealed statistically significant variations in self-management subscale and residence, marital status, and learning style $(\mathrm{t}=3.698, \mathrm{P}=0.001 ; \mathrm{t}=$ 2.054, $\mathrm{P}=0.041$; and $\mathrm{F}=4.112, \mathrm{P}=0.008$, respectively). Means of the desire for learning subscales were statistically significant for gender $(\mathrm{t}=1.985, \mathrm{P}=0.048)$, academic level $(\mathrm{F}=2.969, \mathrm{P}=0.033)$, and mode $(\mathrm{t}=$ $3.610, P=0.001)$. Self-control means were variant in learning style $(F=4.280, P=0.007)$ and mode $(t=6.694, P$ $=0.001)$. The overall SDLR scores were statistically significant for residence $(t=4.938, P=0.001)$ and learning style $(\mathrm{F}=5.197, \mathrm{P}=0.002)$. Post-hoc analysis indicated statistically significant differences in desire for learning In addition, the self-management and self-control subscales of SDLR showed significant relation with students' learning styles while desire for zzlearning had no significant association (Aljohani \& Fadila, 2018).

One more study assessed the relationship between the self-directed learning and learning styles used by students. Results of the study clearly showed that there are no significant differences between self-directed learning readiness and the four learning styles as defined by the LSI. This study also concluded that, self-directed learning readiness has a significant relation with all learning styles instead of being particular one

Correlation of the learning styles with self-learning readiness as well as with the teaching preferences in nursing education was determined by a survey study which used the tools by Guglielmino (Self-directed Learning Readiness Scale) and Kolb (Learning Style Inventory). In the survey, list of teaching methods were asked by the participants to be ranked. Results showed the use of active learning styles by more than $75 \%$ of the learners. Study also revealed that: learner nurses get lesser inclined towards SDL as their training years pass; and that the methods of lectures and experiential learning practices applied at the nursing training schools are lesser preferred by the student nurses dealing in psychiatry and mentally handicapped patients domain (Şenyuva \& Kaya, 2015).

\section{METHODS}

\section{Research design}

The study used a correlation descriptive design in order to describe the variables and also assess the relationships among these variables.

\section{Study settings}

The study was carried out at a nursing school of the university.

\section{Participants}

Participants were selected for this study using the non-probability convenience sampling. All the nursing students regardless of gender will be invited to participate in the study and those will be chosen for sample data who are available the time of data collection.

\section{Study Population:}

This study will include population from the School of Nursing, University Lahore.

\section{Sample Size:}

In order to determine sample size, formula of "Slovin's 1960' was used that is as follows:

$\mathrm{n}=$

$$
\mathrm{N} \overline{1+\mathrm{N}(\mathrm{e})^{2}}
$$

where $\mathrm{n}$ is the size of sample, $\mathrm{N}$ is the size of population and e is the acceptable sampling error. Putting values according to the study,

$$
\begin{aligned}
& \mathrm{n}=\frac{230}{1+230(0.05)^{2}} \\
& \mathrm{n}=\frac{230}{1+230(0.0025)} \\
& \mathrm{n}=\frac{230}{1+0.575}
\end{aligned}
$$




$$
\begin{aligned}
& \mathrm{n}=\frac{230}{1.575} \\
& \mathrm{n}=146 \text { (AbuAssi \& Alkorashy, 2016) }
\end{aligned}
$$

\section{Sampling method}

The study will select participants using the non-probability convenience sampling.

\section{Study Duration}

Duration of the study was of five months from Jan 2019 to May 2019.

\section{Inclusion Criteria}

All male and female nursing students having age 20 to 45 years from the school of nursing University, Lahore and who are willing to participate was included in this study.

\section{Exclusion Criteria}

Midwifery Student and students having age less than 15 years and above 45 years was excluded. Nursing Students who are not interested and not willing to participate was excluded. Male nurses were also excluded in this study

Data gathering plan

Data collection for the study was done through questionnaires that will contain close-ended questions. The questionnaires will be distributed among the nursing students of University of Lahore which will contain questions related to demographics as well as two scaled to determine the relationship of learning styles with SDL in the nursing students.

\section{Instruments}

The study was collected data through a questionnaire that will be translated in English language. In order to develop the questionnaire, two instruments chosen will be

i. $\quad$ Learning style inventory (LSI) and

ii. $\quad$ SDLR scale

Socio-demographic characteristics of the participants. There will be three parts of the questionnaire:

\section{Part I: Demographic characteristics}

There was fives questions in this part and these will target the participants' demographic characteristics i.e. age, gender, marital status, academic level and living status (either with family or in the university hostel).

\section{Part II: Learning styles inventory}

There were twelve complete sentences in this part and each sentence has to be answered out of four possible ones ranking from four (high) to one (low). These answers will not be absolute but will be a description about respondents' learning preferences. The responses will then be tallied and arranged for determining preferences of learning style for example converging, accommodating, assimilating or diverging. Moreover, two distinct dimensions against four learning categories will also be assessed using this instrument which are reflective observation $\mathrm{RO}$ versus active experimentation $\mathrm{AE}$ and concrete experience $\mathrm{CE}$ versus abstract conceptualization AC (Kolb, 1984).

\section{Part III: Readiness for Self-directed learning}

The third part consists of SDLR self-directed learning readiness scale was developed by Fisher et al. (2001) and revised by Fisher and King (2010). SDLR scale is set particularly for the nursing education as it assists the teachers in understanding preferences, abilities and attitudes necessary to be possessed for self-directed learning. The scale comprises of 40 items where these items are grouped in three categories such that each category acts as sub-scale that include learning desire $(\mathrm{n}=12)$, self-management $(\mathrm{n}=13)$ and and self-control $(\mathrm{n}=15)$. In these categories, responses by participants will be recorded using 5 point Likert scale that ranges from $1=$ strongly disagree to $5=$ strongly agree.

\section{ETHICAL CONSIDERATION}

The rules and regulations set by the ethical committee of Lahore school of nursing was followed while conducting the research and the rights of the research participants was respected.

Written informed consent attached will be taken from all the participants.

- All information and data collection will be kept confidential.

Data analysis was analyzed on SPSS (version 23).

- Baseline demographic variables was analyzed in tables showing frequency and percentage distribution.

- $\quad$ Pearson correlation test was used to see the correlation between variables.

\section{RESULTS}

This chapter consists of five sections. Section 1 represents the demographic characteristics of the participants. Section two show the normality distribution of data. Section three displays the reliability and validity of tools of variables. Section four is about description of statistics and section 5 represents the correlation of variables and sub variables. 
Section 1

This section represents the distribution of nursing students by demographic characteristics. This demographic data describes in table and it includes gender, age group, marital status and qualification of participants. Results of demographic characteristics of participants are summarized in terms of frequency and percentage.

\section{Table 4.1}

Demographic Data Analysis

\begin{tabular}{|c|c|c|c|}
\hline \multirow[t]{2}{*}{ Characteristics } & \multirow[t]{2}{*}{ Category } & Respondents & \\
\hline & & Number & Percent \\
\hline \multirow[t]{3}{*}{ Gender } & Male & 29 & $20.7 \%$ \\
\hline & Female & 111 & $79.3 \%$ \\
\hline & Total & 140 & 100 \\
\hline \multirow[t]{5}{*}{ Age } & $20-25$ yrs & 17 & $12.1 \%$ \\
\hline & $26-30 \mathrm{yrs}$ & 56 & $40.3 \%$ \\
\hline & $31-35$ yrs & 51 & $36.4 \%$ \\
\hline & $36-40 \mathrm{yrs}$ & 16 & $11.4 \%$ \\
\hline & Total & 140 & 100 \\
\hline \multirow[t]{4}{*}{ Marital status } & Married & 47 & $33.6 \%$ \\
\hline & Unmarried & 92 & $65.7 \%$ \\
\hline & Diploma in Nursing & 65 & $46.4 \%$ \\
\hline & Bachelor in Nursing & 75 & $53.9 \%$ \\
\hline \multirow[t]{3}{*}{ Qualification } & Master in Nursing & 0 & $0 \%$ \\
\hline & Others & 0 & $0 \%$ \\
\hline & Total & 140 & 100 \\
\hline
\end{tabular}

Table 1 presents the selected demographic characteristics of the participants. The total number of participants in this study were 140. The four selected demographic characteristics were age, gender, academic level and marital status. . More than half of the participants were female $(79.3 \%)$ and remaining participants were male (27.3\%).More than half of the participants were in the $26 \geq 30$ age group (40.3\%) and almost half participants were in 31-35 age group (36.4\%) and remaining participants were in 30-40 age group $(11.4 \%)$. About one third of the participants were Qualified in Diploma Nursing (46.4\%) and 52.9\% were qualified in Bachelor in Nursing. Most participants were unmarried (65.7\%) and only 33.6\% participants were married.

\section{Table 4.2 Normality of data}

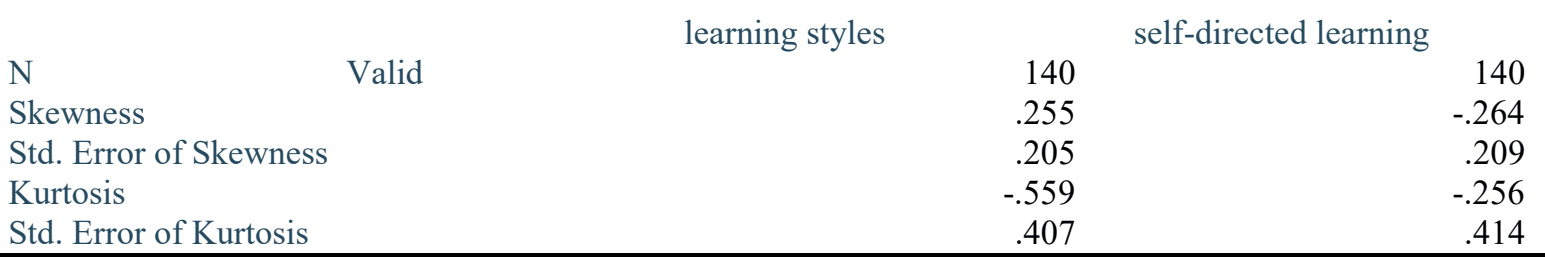

Table 4.2 showed the Skewness and kurtosis value of independent variable learning styles and dependent variable self-directed learning. Skewness value of learning styles was (.255) and self-directed learning was $(-.264)$.Kurtosis value of learning styles was (-.559) and self-directed learning was $(-.256)$, it indicated that the data was perfectly symmetrical. Normal distribution of the data was equal under the curve.

Table 4.3 Reliability of learning style inventory scale

\begin{tabular}{|l|l|l|}
\hline \multicolumn{2}{|l|}{ Reliability Statistics } & N of Items \\
\hline Cronbach's Alpha & Cronbach's Alpha Based on Standardized Items & .215 \\
\hline .840 & & 12 \\
\hline
\end{tabular}

Table 4.7showing reliability of learning style inventory scale that value of cronbach's Alpha was (.840) which was $<0.7$. It indicated that learning style inventory scale was reliable for the study.

\section{Section 5}

Table 4.4 Reliability of self-directed learning scale

\begin{tabular}{|l|l|l|}
\hline \multicolumn{2}{|l|}{ Reliability Statistics } & N of Items \\
\hline Cronbach's Alpha & Cronbach's Alpha Based on Standardized Items & .922 \\
\hline .957 & & 40 \\
\hline
\end{tabular}

Table 4.4 showing reliability of self-directed learning scale that value of cronbach's Alpha was (.957) which was $<0.7$. It indicated that learning style inventory scale was reliable for the study. 
Table 4.5 Correlation between learning style inventory and self-directed learning readiness

\begin{tabular}{llrr}
\hline & \multicolumn{2}{c}{ learning stylesmean2 } \\
\hline learning styles & Pearson Correlation & $1.233^{* *}$ \\
& Sig. (2-tailed) & .006 \\
N & 140 & 138 \\
Self-directed learningPearson Correlation & $.233^{* *}$ & 1 \\
& Sig. (2-tailed) & .006 & \\
N & 140 & 140 \\
$* *$ Correlation is significant at the 0.01 level (2-tailed). & \\
\hline
\end{tabular}

Table 4.5 represents the co relation between learning styles and self-directed learning p value was (.006) and Pearson correlation was $\left(.233^{* *}\right)$. It indicated that learning styles and self-directed learning readiness had a significant positive relationship with each other $\left(\mathrm{r}=.233^{* *} \mathrm{p} 0.006<0.05\right)$.

\section{DISCUSSION}

The current study was conducted to determine the presence of a relationship between nursing students' learning styles and self-directed learning readiness. The learning styles and levels of readiness for SDL should be considered as key factors for improving the curriculum and nursing education, and for creating learning opportunities. The findings of the present study support the findings of previous study conducted and Turkey on nursing students enrolled in an accelerated graduate course. The academic performance and achievements of the nursing students were compared with changes in the environment of learning and with the teaching style and assessment of the nursing educators(Avdal, 2013).

Overall, the findings of the study revealed that there was an association between the learning styles and the self-directed learning readiness among the nursing students. In addition, the subscales of SDLR, namely, selfmanagement, desire for learning, and self-control, showed significant association with learning styles. These findings were similar to the findings of two previous study conducted in Taliban This study revealed that participants prefer to learn using unimodal VARK modalities, and the dominant learning style was kinesthetic. The participants' level of readiness for SDL and their self-control were high compared to the other SDLR subscales. The results showed a significant connection between the participants' learning styles and the variables of their readiness for SDL (Guraya, Guraya, Habib, \& Khoshhal, 2014).

Moreover, the findings showed that the most effective self-directed learning approach among most nursing students in current study was the accommodator style followed by Assimilator. This style relies primarily on the characteristics of $\mathrm{CE}$ and RO. The Diverging style s was the least preferred style. These findings are similar to the previous research conducted in CEU University the study revealed that most of the nursing students were independent learners $(52 \%)$. There were no dependent learners but since several respondents who were uncertain $(48 \%)$, it is the role of nurse educators to develop their independence in learning. all the four types of learning styles namely: Accommodative, Convergent, Assimilative and Divergent; were present showing the variation in learning styles of nursing students. But it was found out that they mostly prefer the Convergent learning style, especially the junior and senior students. The study concluded that there was no relationship between the variables: demographic profile, self-directed learning readiness and learning style. However, the scores of convergent learning style were higher than that of divergent and accommodative in their self-directed learning readiness (Raphael \& Pearl, 2017).

\section{CONCLUSION}

The findings of the current study showed that the dominant learning style of the majority of nursing students was the Accommodating style. Moreover, the participants' level of readiness for SDL was low although their selfcontrol was high compared to other SDLR subscales. The results showed significant connection between the participants' learning styles and the variables of their readiness for self-directed learning readiness.

\section{LIMITATIONS}

The quantitative study was carried out with nursing students in a single university, which was a limited yet diverse population. The single location and the limited number of participants (compared to all nursing students in the target population) may have limited the generalization of the findings to other higher institutions of nursing education.

Furthermore, both the SDLR and the LSI were self-reporting questionnaires, which carried the risk of subjective bias: that is, one's perception of self may have differed from the perceptions of others.

The participation of the nursing students was voluntary, which may have affected the validity of the sample.

\section{RECOMMENDATIONS}

Based on the findings and limitations of this research study, the following recommendations are offered: 
1) Replicate this study using larger samples and sub-samples of the population.

2) Conduct research to include more than one college and/or university in order to generalize the findings to the entire population of the nursing students.

\section{REFERENCES}

AbuAssi, N. E., \& Alkorashy, H. A. E. (2016). Relationship between learning style and readiness for self-directed learning among nursing students at king Saud university, Saudi Arabia. International Journal of Advanced Nursing Studies, 5(2), 109-116.

Adeoye-Agboola, D. I., \& Evans, H. (2015). The Relationship Between Anxiety and Academic Performance of Postgraduate International Students in a British University: A Cross-Sectional Quantitative Design. Science, $3(3), 331-338$.

Aljohani, K. A., \& Fadila, D. E. S. (2018). Self-directed learning readiness and learning styles among Taibah nursing students. Saudi Journal for Health Sciences, 7(3), 153.

Avdal, E. Ü. (2013). The effect of self-directed learning abilities of student nurses on success in Turkey. Nurse education today, 33(8), 838-841.

El-Gilany, A.-H., \& Abusaad, F. E. S. (2013). Self-directed learning readiness and learning styles among Saudi undergraduate nursing students. Nurse education today, 33(9), 1040-1044.

Gebru, A. A., Sh, G., \& Mohammadi, N. (2015). The Relationship between Learning Style, Self-Directed in Learning and Undergraduate Nursing Students' Academic Achievement in Tehran University of Medical Science (TUMS). American Journal of Nursing Science, 4(3), 138-150.

Guraya, S. S., Guraya, S. Y., Habib, F. A., \& Khoshhal, K. I. (2014). Learning styles of medical students at Taibah University: trends and implications. Journal of research in medical sciences: the official journal of Isfahan University of Medical Sciences, 19(12), 1155.

Kolb, D. A., Boyatzis, R. E., \& Mainemelis, C. (2001). Experiential learning theory: Previous research and new directions. Perspectives on thinking, learning, and cognitive styles, 1(8), 227-247.

McLeod, S. (2010). Kolb's learning styles and experiential learning cycle. Simply psychology.

Örs, M. (2018). The Self-Directed Learning Readiness Level of the Undergraduate Students of Midwife and Nurse in Terms of Sustainability in Nursing and Midwifery Education. Sustainability, 10(10), 3574.

Ranvar, S. (2015). The relationship between self-directed learning and the parameters affecting adult education. European Online Journal of Natural and Social Sciences, 4(3), pp. 489-499.

Raphael, M. V., \& Pearl, C. (2017). Relationship between level of readiness for self-directed learning and learning styles of CEU nursing students. Philippine Journal of Nursing, 87(1), 61-65.

Şenyuva, E., \& Kaya, H. (2015). The correlation Between Self-directed Learning Readiness and Web-based Learning in Nursing Students: A Study Conducted in Turkey. Stanisław Juszczyk, 98.

Shen, W.-q., Chen, H.-l., \& Hu, Y. (2014). The validity and reliability of the self-directed learning instrument (SDLI) in mainland Chinese nursing students. BMC medical education, 14(1), 108.

AbuAssi, N. E., \& Alkorashy, H. A. E. (2016). Relationship between learning style and readiness for self-directed learning among nursing students at king Saud university, Saudi Arabia. International Journal of Advanced Nursing Studies, 5(2), 109-116.

Adeoye-Agboola, D. I., \& Evans, H. (2015). The Relationship Between Anxiety and Academic Performance of Postgraduate International Students in a British University: A Cross-Sectional Quantitative Design. Science, 3(3), 331-338.

Aljohani, K. A., \& Fadila, D. E. S. (2018). Self-directed learning readiness and learning styles among Taibah nursing students. Saudi Journal for Health Sciences, 7(3), 153.

Avdal, E. Ü. (2013). The effect of self-directed learning abilities of student nurses on success in Turkey. Nurse education today, 33(8), 838-841.

El-Gilany, A.-H., \& Abusaad, F. E. S. (2013). Self-directed learning readiness and learning styles among Saudi undergraduate nursing students. Nurse education today, 33(9), 1040-1044.

Gebru, A. A., Sh, G., \& Mohammadi, N. (2015). The Relationship between Learning Style, Self-Directed in Learning and Undergraduate Nursing Students' Academic Achievement in Tehran University of Medical Science (TUMS). American Journal of Nursing Science, 4(3), 138-150.

Guraya, S. S., Guraya, S. Y., Habib, F. A., \& Khoshhal, K. I. (2014). Learning styles of medical students at Taibah University: trends and implications. Journal of research in medical sciences: the official journal of Isfahan University of Medical Sciences, 19(12), 1155.

Kolb, D. A., Boyatzis, R. E., \& Mainemelis, C. (2001). Experiential learning theory: Previous research and new directions. Perspectives on thinking, learning, and cognitive styles, 1(8), 227-247.

McLeod, S. (2010). Kolb's learning styles and experiential learning cycle. Simply psychology.

Örs, M. (2018). The Self-Directed Learning Readiness Level of the Undergraduate Students of Midwife and Nurse in Terms of Sustainability in Nursing and Midwifery Education. Sustainability, 10(10), 3574. 
Ranvar, S. (2015). The relationship between self-directed learning and the parameters affecting adult education. European Online Journal of Natural and Social Sciences, 4(3), pp. 489-499.

Raphael, M. V., \& Pearl, C. (2017). Relationship between level of readiness for self-directed learning and learning styles of CEU nursing students. Philippine Journal of Nursing, 87(1), 61-65.

Şenyuva, E., \& Kaya, H. (2015). The correlation Between Self-directed Learning Readiness and Web-based Learning in Nursing Students: A Study Conducted in Turkey. Stanisław Juszczyk, 98.

Shen, W.-q., Chen, H.-l., \& Hu, Y. (2014). The validity and reliability of the self-directed learning instrument (SDLI) in mainland Chinese nursing students. BMC medical education, 14(1), 108. 